\title{
COMMENTARY
}

\section{When to start dialysis in patients with acute kidney injury? When semantics and logic become entangled with expectations and beliefs}

\author{
Norbert Lameire*, Wim Vanbiesen and Raymond Vanholder \\ See related research by Chou et al., http://ccforum.com/content/15/3/R134
}

\begin{abstract}
Earlier initiation of dialysis may have a beneficial impact on survival of critically ill patients with acute kidney injury (AKI). A retrospective analysis in the previous issue of Critical Care showed that early initiation of renal replacement therapy (RRT), as defined by RIFLE criteria, was not associated with a reduction in hospital mortality. The retrospective character of many studies describing the results of early RRT initiation and the validity of RIFLE criteria to determine the need for dialysis can be questioned, in particular when urinary output is not considered. Initiating dialysis in AKI should be based on clinical criteria and not on serum creatinine or another serum/urine-based biomarker.
\end{abstract}

In the previous issue of Critical Care, Chou and colleagues [1] report that early initiation of renal replacement therapy (RRT), as defined by RIFLE criteria, was not associated with reduction in hospital mortality in patients with acute kidney injury (AKI) and sepsis.

The timing of initiation of RRT has been a controversial issue for many years in both patients suffering from chronic kidney disease [2] and those suffering from acute kidney disease [3]. A recently published systematic review and meta-analysis on this topic concluded that earlier initiation of RRT in critically ill AKI patients may have a beneficial impact on survival but that, in the absence of new evidence from suitably designed randomized trials, a definitive treatment recommendation cannot be made [3].

The idea that 'earlier' initiation of treatment should be beneficial stems from our belief that sometimes complex

*Correspondence: norbert.lameire@ugent.be

Renal Division, University Hospital Gent, 185 De Pintelaan, 9000 Gent, Belgium interventions may change the course of a disease. In the case of AKI and sepsis, it has been hypothesized that early dialysis in sepsis can reduce circulating levels of inflammatory substances and may therefore beneficially impact on the pathophysiological mechanisms of the disease. Unfortunately, the validity of this premise has never been proven, and existing evidence points rather in the opposite direction [4]. Both literature data and the currently published study once more confirm that patients with sepsis die with AKI rather than of AKI: no single indicator of renal function or kidney injury was predictive of mortality in the multivariate model as it was applied by Chou and colleagues [1]. In the patient group with septic AKI, dialysis should not be seen as a curative intervention, but rather as supportive therapy, preventing the patient from dieing from hyperkalaemia or fluid overload during the period the kidneys are temporarily failing. As a consequence, early dialysis, in the semantic meaning of 'intervention before support is needed', exposes patients to side effects of the treatment without really helping them.

Problematic for correct interpretation of the data in nearly all studies, including the one by Chou and colleagues, is the fact that virtually all are retrospective. This complicates the interpretation at various levels. As strict clinical rules on the timing of initiation of dialysis were present in these ICUs during the collection of these data, all patients in fact started at the same 'time point' in their disease, that is, when they fulfilled one of the preset criteria. As such, the categorization 'early versus late' loses the semantic significance of a 'time-related event', and in fact no conclusions on timing can be made. Conclusions on the impact of 'early versus late initiation of dialysis' would only be justified when, at the moment patients fulfilled the criteria for dialysis, one group started RRT immediately while for the other group dialysis was delayed for one or more days. In the only available randomized controlled trials in this field, early versus late was defined by the urinary output versus 
biochemical values [5,6] or by magnitude of urinary output [7]. One important aspect of the current paper by Chou and colleagues [1] is that the RIFLE criteria have no value in determining the need for dialysis, as equal numbers of patients within the different RIFLE categories were apparently started on dialysis. Indeed, if RIFLE were a good predictor of need for dialysis, one would expect that there was a preponderance of RIFLE class 'I' or ' $F$ ' in the cohort of dialyzed patients, quod non.

Unfortunately, the study does not provide data on the distribution of the different RIFLE categories in the nondialyzed patients, but we would not be surprised that these RIFLE categories were exactly comparable to those in the dialyzed cohort. RIFLE is a scoring system developed to grade prognosis of acute renal injury, and although it performs quite well at the cohort level, its applicability to individual patient outcome is rather poor. The RIFLE criteria were not developed to predict the need for dialysis. This is even more true in the current study, as the most powerful component of the RIFLE criteria, urine output, was not taken into account. As a consequence, the correct conclusion of the current data should thus be that serum creatinine is not a good parameter to use for determining when to start dialysis in AKI patients, just as has been found in patients with chronic kidney disease [8]. The omission of urine output as a parameter is critical, especially as fluid overload (central venous pressure $>12 \mathrm{mmHg}$ ) was a criterion to start dialysis. The combination of evaluation of fluid status and urine output, and especially the evolution over time of these two parameters, is probably one of the major decisive criteria to start dialysis at present. When the patient is euvolemic, or even volume overloaded, and still remains oliguric despite maximal support, one should not await further organ damage, and dialysis should be initiated [9]. In addition, as only patients who did actually start dialysis were included, it is difficult to guess what happened to patients with classes RIFLE 0 or I who did not start dialysis. It is likely that these patients had a better survival than those who did start dialysis, and then, the conclusion of the study would be that early initiation of dialysis based on RIFLE criteria is detrimental. Such a conclusion is different from the statement that early initiation of dialysis based on RIFLE criteria in patients with sepsis does not reduce mortality.

In conclusion, the question whether dialysis in AKI should be started early or late remains unanswered. Maybe we cannot answer this question now because it may be the wrong question: as dialysis is supportive and not curative, patients either need dialysis, in which case it should not be delayed, or they do not need dialysis, in which case it can only harm. What we need is a set of accepted indications for dialysis in AKI. Once we have agreed on those, the timely initiation of dialysis in those who are predicted to inevitably progress to one of those conditions seems the most appropriate strategy. In contrast, with current practice, it seems unlikely that serum creatinine or another serum/urine-based biomarker will be one of those criteria.

\section{Abbreviations}

AKI, acute kidney injury; RRT, renal replacement therapy.

\section{Competing interests}

The authors declare that they do not have any competing interests.

Published: 8 July 2011

References

1. Chou YH, Huang TM, Wu VC, Wang CY, Shiao CC, Lai CF, Tsai HB, Chao CT, Young GH, Wang WJ, Kao TW, Lin SL, Han YY, Chou A, Lin TH, Yang YW, Chen YM, Tsai PR, Lin YF, Huang JW, Chiang WC, Chou NK, Ko WJ, Wu KD, Tsai TJ, Nsarf Study Group T: Impact of timing of renal replacement therapy initiation on outcome of septic acute kidney injury. Crit Care 2011, 15:R134

2. Lameire N, Van BW: The initiation of renal-replacement therapy - just-intime delivery. N Engl J Med 2010, 363:678-680.

3. Karvellas CJ, Farhat MR, Sajjad I, Mogensen SS, Leung AA, Wald R, Bagshaw SM: A comparison of early versus late initiation of renal replacement therapy in critically ill patients with acute kidney injury: a systematic review and meta-analysis. Crit Care 2011, 15:R72.

4. De Vriese AS, Colardyn FA, Philippe JJ, Vanholder RC, De Sutter JH, Lameire $\mathrm{NH}$ : Cytokine removal during continuous hemofiltration in septic patients. J Am Soc Nephrol 1999, 10:846-853.

5. Bouman CS, Oudemans-van Straaten HM, Tijssen JG, Zandstra DF, Kesecioglu J: Effects of early high-volume continuous venovenous hemofiltration on survival and recovery of renal function in intensive care patients with acute renal failure: a prospective, randomized trial. Crit Care Med 2002, 30:2205-2211.

6. Elahi MM, Lim MY, Joseph RN, Dhannapuneni RR, Spyt TJ: Early hemofiltration improves survival in post-cardiotomy patients with acute renal failure. Eur J Cardiothorac Surg 2004, 26:1027-1031.

7. Sugahara S, Suzuki H: Early start on continuous hemodialysis therapy improves survival rate in patients with acute renal failure following coronary bypass surgery. Hemodial Int 2004, 8:320-325.

8. Tattersall J, Dekker $F$, Heimbürger $\mathrm{O}$, Jager $\mathrm{KJ}$, Lameire $\mathrm{N}$, Lindley $\mathrm{E}$, Van Biesen W, Vanholder R, Zoccali C; on behalf of the ERBP Advisory board: When to start dialysis: updated guidance following publication of the Initiating Dialysis Early and Late (IDEAL) study. Nephrol Dial Transplant 2011, 26:2082-2086.

9. Macedo E, Malhotra R, Claure-Del GR, Fedullo P, Mehta RL: Defining urine output criterion for acute kidney injury in critically ill patients. Nephrol Dial Transplant 2011, 26:509-515.

doi:10.1186/cc10280

Cite this article as: Lameire $\mathrm{N}$, et al:: When to start dialysis in patients with acute kidney injury? When semantics and logic become entangled with expectations and beliefs. Critical Care 2011, 15:171. 